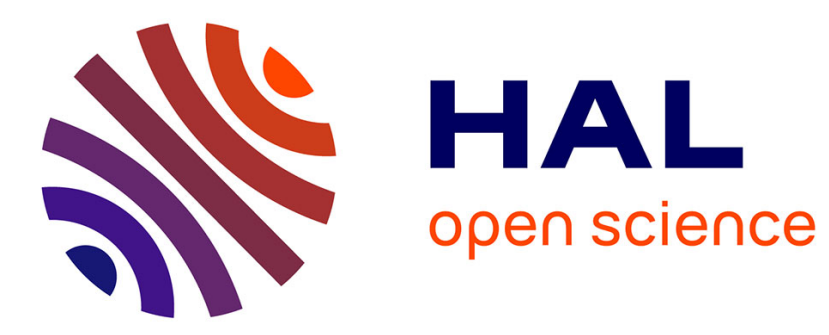

\title{
Determination of the surface geostrophic velocity field from satellite altimetry \\ Young-Hyang Park
}

\section{To cite this version:}

Young-Hyang Park. Determination of the surface geostrophic velocity field from satellite altimetry. Journal of Geophysical Research, 2004, 109, pp.C05006. 10.1029/2003JC002115 . hal-00164938

\section{HAL Id: hal-00164938 \\ https://hal.science/hal-00164938}

Submitted on 29 Jan 2021

HAL is a multi-disciplinary open access archive for the deposit and dissemination of scientific research documents, whether they are published or not. The documents may come from teaching and research institutions in France or abroad, or from public or private research centers.
L'archive ouverte pluridisciplinaire HAL, est destinée au dépôt et à la diffusion de documents scientifiques de niveau recherche, publiés ou non, émanant des établissements d'enseignement et de recherche français ou étrangers, des laboratoires publics ou privés. 


\title{
Determination of the surface geostrophic velocity field from satellite altimetry
}

\author{
Young-Hyang Park \\ Département des Milieux et Peuplements Aquatiques, Muséum National d'Histoire, Paris, France \\ Received 2 September 2003; revised 5 February 2004; accepted 24 February 2004; published 4 May 2004.
}

[1] Presently available marine geoid models are not accurate enough to extract the mean surface circulation directly from satellite altimetry. A novel method for estimating the mean velocity field of major ocean current systems is derived from the free surface boundary condition. With a given quasi-geostrophic balance for the horizontal surface flow, a scaling analysis of this boundary condition indicates that although the vertical velocity $w$ is mostly balanced by the local change of the free surface, $\partial \eta^{\prime} / \partial t$, useful information on the mean current $(\bar{u}, \bar{v})$ is contained in a small ageostrophic departure $\left(\partial \eta^{\prime} / \partial t-w\right)$. Our method consists in the development of a simple algebraic equation with two unknowns $(\bar{u}, \bar{v})$ and an adjustable parameter $\widetilde{\alpha}$ associated with $\partial \eta^{\prime} / \partial t$, assuming that the latter is proportional to $\left(\partial \eta^{\prime} / \partial t-w\right)$. Most interestingly, $\partial \eta^{\prime} / \partial t$ and all other coefficients of the equation can be determined from altimetry. The altimeter data used is combined TOPEX/Poseidon-ERS gridded data, and the solution is obtained by least squares, minimizing the contribution from the time-variable part of the parameter $\widetilde{\alpha}$ and prescribing the zonal direction of the mean current. The method, which is found to be particularly useful for quasi-zonal high-energy current systems, has been validated against direct observations in the Gulf Stream and Southern Ocean. Comparisons with direct observations and Monte Carlo experiments suggest an overall solution error of about $10 \mathrm{~cm} \mathrm{~s}^{-1}$. Once calibrated against regional velocity statistics, this method will be able to determine from altimetry the mean or instantaneous surface velocity field down to the frontal scale, with a realism that has been inaccessible because of the geoid constraint. INDEX TERMS: 4512 Oceanography: Physical: Currents; 4528 Oceanography: Physical: Fronts and jets; 4556 Oceanography: Physical: Sea level variations; KEYWORDS: altimetry, method, velocity field

Citation: Park, Y.-H. (2004), Determination of the surface geostrophic velocity field from satellite altimetry, J. Geophys. Res., 109, C05006, doi:10.1029/2003JC002115.

\section{Introduction}

[2] Satellite altimetry is a powerful tool for observing the sea surface height (SSH) globally and quasi-synoptically. For example, the TOPEX/Poseidon (T/P) satellite launched in August 1992 into a 1300-km orbit is still providing highly accurate (to $2 \mathrm{~cm}$ ) SSH measurements relative to the Earth's center every 10 days [Fu and Cazenave, 2001]. Dynamic height associated with surface currents is defined as the SSH relative to the geoid, and its accuracy is thus subject to errors in the model geoid. The SSH at a given point can be decomposed into two components: a time-mean height and a time-variable residual height. The former contains the geoid error but the latter does not because the geoid is removed by the residual height calculation. The currently best available geoid has decimeter accuracy at scales shorter than about $2000 \mathrm{~km}$ [Nerem et al., 1994], so it is inadequate for the determination of time-mean ocean currents at these length scales. It is therefore not surprising that most work with altimetry has been devoted to the time-variable part of SSH.
[3] A few attempts to determine the mean velocity field from altimetry have been made, however, either by fitting a synthetic current profile to residual altimetric heights [Kelly and Gille, 1990; Qiu et al., 1991; Gille, 1994] or by using a time average of a simplified vorticity equation [Feron et al., 1998]. We present here a simple method based on the free surface boundary condition. It has been tested in the Gulf Stream area and in the Crozet Basin of the Southern Ocean, which in turn have been validated against direct current observations in those areas. Our method (referred to also as the "Method" to distinguish it from other methods) is shown to be highly promising by furnishing a realistic mean or instantaneous current field from satellite altimetry.

\section{Method}

\subsection{Formulation}

[4] The Method is based on the boundary condition at the free sea surface $z=\eta(x, y, t)$,

$$
w=\frac{d \eta}{d t}=\frac{\partial \eta}{\partial t}+u \frac{\partial \eta}{\partial x}+v \frac{\partial \eta}{\partial y}
$$


where $u, v$, and $w$ are, respectively, the eastward, northward, and vertical velocity components in Cartesian coordinates $(x, y, z)$, and $t$ is time. The surface dynamic topography $\eta$ and horizontal surface flow can be decomposed into a timemean part $(\bar{\eta}, \bar{u}, \bar{v})$ and a time-variable part $\left(\eta^{\prime}, u^{\prime}, v^{\prime}\right)$, leading to

$$
w=\frac{\partial \eta^{\prime}}{\partial t}+\left(\bar{u}+u^{\prime}\right) \frac{\partial\left(\bar{\eta}+\eta^{\prime}\right)}{\partial x}+\left(\bar{v}+v^{\prime}\right) \frac{\partial\left(\bar{\eta}+\eta^{\prime}\right)}{\partial y} .
$$

We consider the time-mean flow as purely geostrophic, i.e.,

$$
(\bar{u}, \bar{v})=\left(-\frac{g}{f} \frac{\partial \bar{\eta}}{\partial y}, \frac{g}{f} \frac{\partial \bar{\eta}}{\partial x}\right)
$$

while the time-variable flow is assumed to be nearly geostrophic, obeying linearized momentum equations

$$
\begin{aligned}
& \frac{\partial u^{\prime}}{\partial t}-f v^{\prime}=-g \frac{\partial \eta^{\prime}}{\partial x} \\
& \frac{\partial v^{\prime}}{\partial t}+f u^{\prime}=-g \frac{\partial \eta^{\prime}}{\partial y},
\end{aligned}
$$

where $g$ is the acceleration due to gravity and $f(=2 \omega \sin \varphi)$ is the Coriolis parameter at a latitude $\varphi$, with $\omega(\approx 7.292 \times$ $10^{-5} \mathrm{~s}^{-1}$ ) representing the angular velocity of the Earth's rotation. Partial differentiating equations (3) and (4) with respect to time, substituting $f v^{\prime}-g \partial \eta^{\prime} / \partial x$ and $-f u^{\prime}-g \partial \eta^{\prime} / \partial y$ for $\partial u^{\prime} / \partial t$ and $\partial v^{\prime} / \partial t$, respectively, and neglecting terms containing second time derivatives (as $\partial^{2} / \partial^{2} \ll f^{2}$ for timescales greater than 10 days that we are interested in), there results

$$
\left(u^{\prime}, v^{\prime}\right)=\left(-\frac{g}{f} \frac{\partial \eta^{\prime}}{\partial y}-\frac{g}{f^{2}} \frac{\partial^{2} \eta^{\prime}}{\partial x \partial t}, \frac{g}{f} \frac{\partial \eta^{\prime}}{\partial x}-\frac{g}{f^{2}} \frac{\partial^{2} \eta^{\prime}}{\partial y \partial t}\right) .
$$

The first two terms on the right-hand side represent the instantaneous geostrophic current, while the second two terms are the secondary, temporal change of geostrophic flow, the so-called isallobaric flow [Gill, 1982]. Introducing equations (2) and (5) into equation (1), we obtain finally

$\frac{1}{f} \frac{\partial^{2} \eta^{\prime}}{\partial y \partial t} \bar{u}-\frac{1}{f} \frac{\partial^{2} \eta^{\prime}}{\partial x \partial t} \bar{v}+\frac{\partial \eta^{\prime}}{\partial t}-\frac{g}{f^{2}}\left(\frac{\partial \eta^{\prime}}{\partial x} \frac{\partial^{2} \eta^{\prime}}{\partial x \partial t}+\frac{\partial \eta^{\prime}}{\partial y} \frac{\partial^{2} \eta^{\prime}}{\partial y \partial t}\right)=w$

$$
10^{-1} U-10^{-1} U+1-\left(10^{-2}+10^{-2}\right)=? .
$$

Apart from $\partial \eta^{\prime} / \partial t$, the interaction of the isallobaric flow with the mean current (first two terms) and eddy current (fourth and fifth terms) gives rise to a vertical velocity. All terms except for $(\bar{u}, \bar{v}, w)$ can be evaluated with reasonable accuracy from altimeter data at each measurement time. For diagnosing the mean current $(\bar{u}, \bar{v})$ from equation $(6 a)$, the vertical velocity $w$ should be eliminated somehow. To this end, a scaling analysis is made relative to the term $\partial \eta^{\prime} / \partial t$, as shown in equation (6b). Characteristic scales used for mesoscale frontal eddy activity are $O\left(10^{5} \mathrm{~m}\right)$ for the horizontal length, $O\left(10^{-1} \mathrm{~m}\right)$ for the residual SSH, $f=O\left(10^{-4} \mathrm{~s}^{-1}\right)$, and $g=$ $O\left(10^{1} \mathrm{~m} \mathrm{~s}^{-2}\right)$. The horizontal time-mean velocity scale $U$ not specified there has units of $\mathrm{m} \mathrm{s}^{-1}$. As the maximum current speed in a high-energy frontal zone is $U=O\left(1 \mathrm{~m} \mathrm{~s}^{-1}\right)$, it is immediately evident that $\partial \eta^{\prime} / \partial t$ is the predominant term and is at least an order of magnitude greater than any other term on the left-hand side of equation (6a). For a more typical current region with $U=O\left(10^{-1} \mathrm{~m} \mathrm{~s}^{-1}\right)$, the dominance of $\partial \eta^{\prime} / \partial t$ increases by 2 orders of magnitude. This implies that most of $\partial \eta^{\prime} / \partial t$ should be balanced by $w$, with only a small fraction of it balanced by the rest. The main balance in equation (6a) is thus just what one would expect from geostrophy. However, our major concern resides in a small ageostrophic departure, because it is that departure that contains information on the mean current.

\subsection{Least Squares Solution}

[5] The basic assumption of the Method is that the difference between $\partial \eta^{\prime} / \partial t$ and $w$ is proportional to $\partial \eta^{\prime} / \partial t$ itself. To allow for some flexibility, the proportionality factor $\widetilde{\alpha}$ is taken to be space and time dependent. More specifically, we define $\widetilde{\alpha}$ such that

$$
\begin{gathered}
\widetilde{\alpha} \frac{\partial \eta^{\prime}}{\partial t}=\frac{\partial \eta^{\prime}}{\partial t}-w \\
\widetilde{\alpha}=\alpha(x, y)+\alpha^{\prime}(x, y, t),
\end{gathered}
$$

which is composed of a time-invariable part $\alpha$ and a timevariable part $\alpha^{\prime}$. Then equation (6a) can be rewritten symbolically as

$$
A \bar{u}+B \bar{v}+C+\alpha D=E,
$$

where $A=\frac{1}{f} \frac{\partial^{2} \eta^{\prime}}{\partial y \partial t}, B=-\frac{1}{f} \frac{\partial^{2} \eta^{\prime}}{\partial x \partial t}, C=-\frac{g}{f^{2}}\left(\frac{\partial \eta^{\prime}}{\partial x} \frac{\partial^{2} \eta^{\prime}}{\partial x \partial t}+\right.$ $\left.\frac{\partial \eta^{\prime}}{\partial y} \frac{\partial^{2} \eta^{\prime}}{\partial y \partial t}\right), D=\frac{\partial \eta^{\prime}}{\partial t}, E=-\alpha^{\prime} \frac{\partial \eta^{\prime}}{\partial t}$. This equation shows different vertical velocity components at each instant and each geographical point. The first two terms arise from the mean current-isallobaric flow interaction; the term $C$ is due to the eddy current-isallobaric flow interaction; the term $\alpha D$ is the vertical velocity associated with the time-invariable parameter $\alpha$; the term $E$ is the vertical velocity associated with the time-variable parameter $\alpha^{\prime}$. At each time step $i$ at a given grid point of altimeter data, equation (9) constitutes the boundary condition at the free surface, namely, $A_{i} \bar{u}+B_{i} \bar{v}+$ $C_{i}+\alpha D_{i}=E_{i}$. Using $\alpha$ as the freely chosen "tuning" parameter, we seek a solution $(\bar{u}, \bar{v})$ which minimizes the sum of $E_{i}^{2}$ over the total measurement period. The Method, by construction, cannot admit the time dependency of $\alpha^{\prime}$ as a tuning parameter. Furthermore, we have no scaling argument for simply neglecting the term $E$ against the other terms. This is because the scaling analysis of equation (6a) with a typical mean velocity $\mathrm{U}=O\left(10^{-1} \mathrm{~m} \mathrm{~s}^{-1}\right)$, together with the definitions of equations (7) and (8), suggests that the magnitude of the term $E$ should be of the same order as all other terms on the left-hand side of equation (9). As a reasonable compromise whose usefulness may be judged by the results, we minimize (not neglect) the contribution from 
the time-variable parameter $\alpha^{\prime}$ (thus the term $E$ ), permitting the solution to respond as much as possible to the timeinvariable tuning parameter $\alpha$. This does not violate the definition of these parameters because no restrictions on their respective contributions are imposed in equations (7) and (8). The least squares solution which makes $\sum E_{i}^{2}$ minimum, regardless of the choice of $(\bar{u}, \bar{v})$, can be obtained by putting $\partial\left(\sum E_{i}^{2}\right) / \partial \bar{u}=0$ and $\partial\left(\sum E_{i}^{2}\right) / \partial \bar{v}=0$, which yields

$$
\begin{aligned}
& \bar{u}= \\
& \frac{\left(\sum A_{i} B_{i} \sum B_{i} D_{i}-\sum B_{i}^{2} \sum A_{i} D_{i}\right) \alpha+\sum A_{i} B_{i} \sum B_{i} C_{i}-\sum B_{i}^{2} \sum A_{i} C_{i}}{\sum A_{i}^{2} \sum B_{i}^{2}-\left(\sum A_{i} B_{i}\right)^{2}}
\end{aligned}
$$

$$
\begin{aligned}
& \bar{v}= \\
& \frac{\left(\sum A_{i} B_{i} \sum A_{i} D_{i}-\sum A_{i}^{2} \sum B_{i} D_{i}\right) \alpha+\sum A_{i} B_{i} \sum A_{i} C_{i}-\sum A_{i}^{2} \sum B_{i} C_{i}}{\sum A_{i}^{2} \sum B_{i}^{2}-\left(\sum A_{i} B_{i}\right)^{2}} .
\end{aligned}
$$

\subsection{Magnitude and Sign of the Parameter $\alpha$}

[6] Previous studies using satellite altimetry indicate a close linkage of high variability regions with those of strong currents [Chelton et al., 1990; Gille, 1994; Park and Gambéroni, 1995; Ducet et al., 2000]. This can be also verified from drifter observations [Fratantoni, 2001]. In estimating the mean velocity of the Antarctic Circumpolar Current (ACC) using a Gaussian jet model, Gille [1994] theoretically demonstrates an excellent correlation between the predicted SSH variability (SSHV) and the modelderived mean velocity, while the altimetric SSHV deviates somewhat from the theory due to some asymmetry existing in real current fields. (SSHV is defined as the root-mean square (rms) of $\eta^{\prime}$ over the altimeter measuring period.) Nonetheless, Gille notes that the theoretical correlation may reasonably serve as a first guess to feed into her model. This observed and theoretically demonstrated close linkage between SSHV and the mean velocity, together with a linear relationship between the latter and $\alpha$ seen in equations (10) and (11), permits us to define the magnitude of $\alpha$ as being proportional, to a first approximation, to the SSHV at each grid point, namely,

$$
\alpha(x, y)=\alpha_{\max }(x) \operatorname{SSHV}(x, y) / \operatorname{SSHV} \max (x) .
$$

Here, $\operatorname{SSHV}_{\text {max }}(x)$ is the $\mathrm{SSHV}$ maximum at a longitude $x$ and $\alpha_{\max }(x)$ is the corresponding maximum magnitude of $\alpha$. This latter quantity is determined by tuning its value to best fit the observed mean velocity profile. Some examples are given in section 3 where we will see that equation (12) serves as an overall rough constraint on current magnitudes. The individual current speed at each grid point is determined by local eddy statistics represented by summation terms in equations (10) and (11). If limited velocity observations are available, $\alpha_{\max }(x)$ may be replaced by its representative value for the whole study area, using a priori information from velocity statistics there.

[7] The sign of $\alpha$ is not determined automatically but depends on the direction of the mean current that we would like to estimate. In fact, the least squares solution of equations (10) and (11) yields a directional ambiguity of $180^{\circ}$, depending on the sign of $\alpha$. Between two possible solutions showing opposite directions at each grid point, we shall take the one with the same direction as climatology. Therefore the a priori knowledge about either the zonal or meridional direction of the mean current is to be provided before applying the Method. As most strong current systems of the world's oceans like the ACC, Gulf Stream, and Kuroshio are dominantly zonal flows, except for some boundary currents closely attached to land, we are mostly concerned with the zonal direction of the mean current, i.e., whether it is locally eastward $(\bar{u}>0)$ or westward $(\bar{u}<0)$. Such information is a prerequisite; the corresponding meridional direction is determined by the Method.

[8] Therefore, useful information on the sign of $\alpha$ may be found in equation (10) that we rewrite in a shorthand expression

$$
\bar{u}=(K \alpha+L) / M,
$$

where $K=\sum A_{i} B_{i} \sum B_{i} D_{i}-\sum B_{i}^{2} \sum A_{i} D_{i}, L=\sum A_{i} B_{i} \sum B_{i} C_{i}-$ $\sum B_{i}^{2} \sum A_{i} C_{i}, M=\sum A_{i}^{2} \sum B_{i}^{2}-\left(\sum A_{i} B_{i}\right)^{2}$. The divisor $M$ is definitively positive, so the sign of $\bar{u}$ is equal to that of the dividend, $K \alpha+L$. Its sign depends on whether the absolute value of $K \alpha$ is greater than that of $L$. If $|K \alpha|>$ $|L|$, the sign of $K \alpha$ is same as that of $\bar{u}$. In other words, $\alpha$ is positive if $\bar{u}$ and $K$ have the same sign and negative if they have different signs. More specifically, for an eastward flow $(\bar{u}>0)$

$$
\alpha>0 \text { if } K>0 \text { and } \alpha<0 \text { if } K<0
$$

but for a westward flow $(\bar{u}<0)$

$$
\alpha<0 \text { if } K>0 \text { and } \alpha>0 \text { if } K<0 \text {. }
$$

Our tests in the Gulf Stream and ACC areas show that these conditions are usually met. If $|K \alpha|<|L|$, however, the sign of $\alpha$ is undetermined because the term $L$ sets the sign of $\bar{u}$, irrespective of the signs of $\alpha$ and $K$. This sometimes appears especially in weak current regions where $\alpha$ is generally small. In this case, $\alpha$ can be set to zero because it can have either sign, although no appreciable difference in velocity estimation is observed even with an arbitrary attribution of the sign. Consequently, a convenient way of determining the sign of $\alpha$ is to compare the sign of $K$ with the supposed direction of $\bar{u}$ within each region of interest, as explained by equations (14) and (15).

\subsection{Altimeter Data and Limitations of the Method}

[9] The altimeter data used in the present study are from the merged T/P and ERS (European Remote Sensing Satellite) altimeter data set [Le Traon and Ogor, 1998] for the 5.3-year period beginning 10 April 1995 (available on

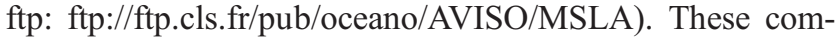
bined altimeter data have previously been interpolated objectively with a space correlation scale of $100 \mathrm{~km}$ and a time correlation scale of 15 days at midlatitudes, providing a reasonable mapping of mesoscale variability, with a regular space $\left(0.25^{\circ}\right.$ in latitude and longitude) and time (every 
10 days) resolution [Ducet et al., 2000]. Partial derivatives of each term on the left-hand side of equation (9) are calculated using a centered difference method, with a space interval of $0.5^{\circ}$ and a time interval of 20 days. Our solution represents therefore the mean geostrophic current at each grid point for about a 5-year period between 1995 and 2000 . It is determined by the statistics of local eddy activity on spatial scales greater than $50 \mathrm{~km}$ and timescales greater than 20 days. Because of the nature of the input data and the calculational methodology employed, smaller scale and higher frequency eddy activity have been excluded from consideration.

[10] Since the Method relies on statistical quantities derived from residual heights $\eta^{\prime}$, the success of this approach depends on the signal-to-noise ratio of the altimeter data. Previous intercomparisons between T/P and tide gauge data in various parts of the world's oceans indicate altimeter measurement errors ranging from 2 to $4 \mathrm{~cm}$, depending mainly on the data smoothing process [Cheney et al., 1994; Mitchum, 1994; Park and Gambéroni, 1995; Verstraete and Park, 1995]. In addition to the formal orbit error of $2 \mathrm{~cm}$ for the combined T/P and ERS altimeters [Le Traon and Ogor, 1998], the gridded altimeter data set used here will also have errors associated with the interpolation procedures. We assume an RMS error of the gridded T/P-ERS data to be $4 \mathrm{~cm}$, although the real value may be somewhat variable depending on the location [Gilson et al., 1998]. If we further assume that the lower limit of a reliably detectable signal is to be at leastM twice the RMS error $(95 \%$ confidence limit of a Gaussian noise), the successful application of the Method may be limited to regions with high eddy activity having local SSHV greater than $8 \mathrm{~cm}$. This value is close to the $7-\mathrm{cm}$ variability contour of Feron et al. [1998], along which the boundary condition of their method is imposed. Gille [1994] notes similarly that the success of her method is contingent on the residual bumps that should be high enough to be detected by the altimeter.

[11] Another limit of the present Method is that it may not be very useful for narrow boundary currents tightly attached to continental boundaries. This is because such boundary currents close to coasts are not well resolved with the present altimeter data interpolated with a space correlation scale of $100 \mathrm{~km}$. Aside from this resolution problem, altimeter data over shallow shelf and coastal regions are subject to greater tidal errors than open ocean regions [Park and Gambéroni, 1995, and references therein]. Moreover, as pointed out by a reviewer, the mean flow in such boundary regions does not undergo substantial variability, and so is less accessible by the present approach. For these reasons, our Method is believed to be best applicable to strong current systems of the open ocean, such as the ACC and the part of the Gulf Stream and Kuroshio that are sufficiently removed from coasts.

\section{Test in the Gulf Stream Area}

[12] The Gulf Stream is the most extensively exploited current system of all the oceans. It presents an energetic quasi-zonal flow, and so should constitute an ideal place to test our Method. Fratantoni [2001] has provided a new compilation of Lagrangian velocity observations that de- scribe the state of the North Atlantic surface circulation during the 1990s. These drifter-derived velocities were obtained by averaging observations within $1^{\circ} \times 1^{\circ}$ boxes [Fratantoni, 2001]. We take Fratantoni's drifter-derived mean velocity field in the Gulf Stream area as a good approximation to reality, against which our Method can be tested and validated. Original unsmoothed altimeter-derived velocity vectors are a little noisy. In order to be compatible with drifter data, the input altimeter data and the solution vectors have been slightly smoothed using a $1^{\circ} \times 1^{\circ}$ binomial filter, suppressing any wavelength fluctuations much shorter than $100 \mathrm{~km}$.

\subsection{Meridional Profiles of Zonal Velocity Across the Gulf Stream Axis}

[13] To test the applicability of the Method by evaluating its capacity to reproduce a well-known mean velocity field, we have first estimated meridional profiles of zonal velocity across the axis of the Gulf Stream. The direction of zonal velocity introduced in the Method is the same as that from the drifter-derived velocity field. Top panels of Figure 1 show the zonal velocity profiles obtained using different $\alpha_{\max }$ values at three selected longitudes compared to the drifter-derived profiles (dashed lines). The best matching (optimal) profiles, i.e., those giving the least RMS differences relative to the drifter data, are shown thickened. The $\alpha_{\max }$ values tuned to obtain those optimal profiles are given in Table 1, together with other statistics of the comparison. The other profiles with the thin lines were obtained by varying $\alpha_{\max }$ every $10 \%$ within a range between $-30 \%$ and $+30 \%$ around the optimal values. The bottom panels of Figure 1 show SSHV profiles, $\alpha$ profiles associated with the optimal $\alpha_{\max }$, and the magnitude of $\alpha$ (dashed lines). The $\alpha$ profiles were obtained by equation (12) for the magnitude and by equations (14) and (15) for their signs. Except for tuning $\alpha_{\max }$, which is our only free parameter, the solution is determined solely by the altimeter data themselves according to equations (10) and (11).

[14] The Gulf Stream axis is correctly reproduced within $0.5^{\circ}$ in latitude, which is the half grid interval of the drifterderived current data. The RMS misfits between the optimal velocity profiles from the Method and drifter-derived velocity profiles range from 9.5 to $6.9 \mathrm{~cm} \mathrm{~s}^{-1}$, decreasing to the east in rough proportion to drifter-derived maximum velocities along the jet axis $\left(63 \mathrm{~cm} \mathrm{~s}^{-1}\right.$ at $70^{\circ} \mathrm{W}$ to $42 \mathrm{~cm} \mathrm{~s}^{-1}$ at $\left.50^{\circ} \mathrm{W}\right)$. Note that the uncertainty of the latter velocities in the area is 2 to $3 \mathrm{~cm} \mathrm{~s}^{-1}$ [Fratantoni, 2001]. The corresponding optimal $\alpha_{\max }$ vary from 0.22 to 0.15 , also roughly proportional to the maximum velocities. Of course, these results are the consequence of tuning, but that is not the whole story. One has to remember that the tuning was applied to one parameter $\alpha_{\max }$ only and that all the profiles over $5^{\circ}$ of latitude were obtained by altimeter data. What is more important is that the general shape of the velocity profile at each longitude is quite similar to observation for any value of $\alpha_{\max }$. Varying $\alpha_{\max }$ induces only an overall, gradual increase or decrease in velocity, with a $10 \%$ change in $\alpha_{\max }$ yielding a few $\mathrm{cm} \mathrm{s}^{-1}$ change in velocity on the average. This is the most pleasing point of the Method, enabling one to estimate a realistic current field by simply tuning $\alpha_{\max }$ over a few values in a given study area. 

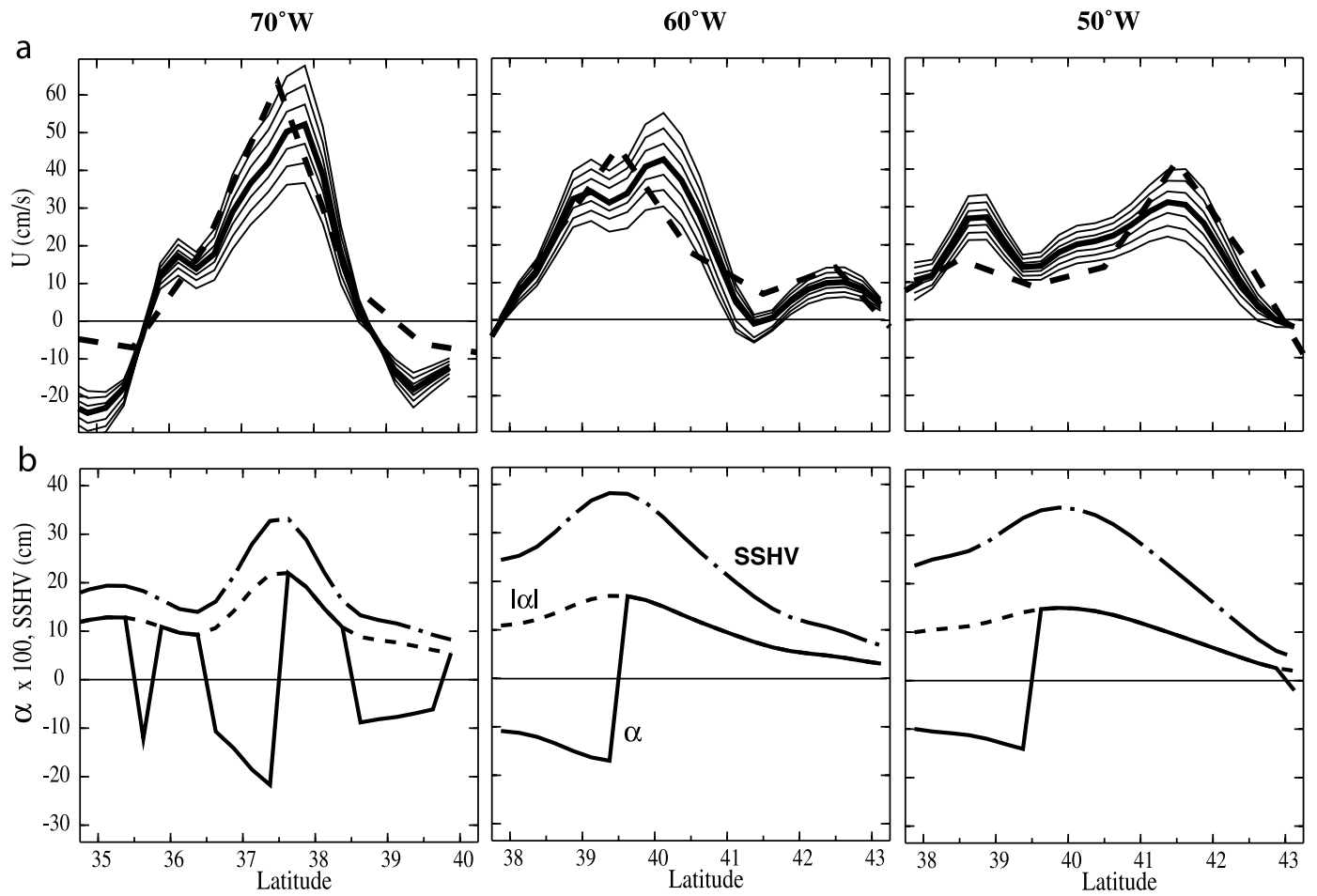

Figure 1. (a) Meridional profiles of zonal velocity across the Gulf Stream axis using different $\alpha_{\max }$ values at three longitudes, compared to those from drifter data (dashed lines) [Fratantoni, 2001]. Bestfitting velocity profiles are shown thickened, and other profiles with thin lines are those obtained by varying $\alpha_{\max }$ every $10 \%$ around the best-fitting $\alpha_{\max }$ within a range of $\pm 30 \%$. (b) Profiles of sea surface height variability (SSHV), $\alpha$ (thick lines) and absolute $\alpha$ (dashed lines) corresponding to the best-fitting velocity profiles. Note that $\alpha$ values are multiplied by 100 for the graphical presentation.

[15] By definition, $\alpha_{\max }$ is the magnitude of $\alpha$ at the location of $\mathrm{SSHV}_{\max }$. However, the jet axis does not always coincide with the location of $\alpha_{\max }$. For example, at $50^{\circ} \mathrm{W}$ there appear double jets in our results, which is also indicative in the drifter-derived velocity profile. The main jet is at $41^{\circ} 30^{\prime} \mathrm{N}$ and the second one just south of $39^{\circ} \mathrm{N}$, while $\alpha_{\max }$ (or $\mathrm{SSHV}_{\max }$ ) is found near $40^{\circ} \mathrm{E}$ where both observed and estimated velocities have their minimum values. Also, $\alpha_{\max }$ values and corresponding maximum velocity estimates do not always increase with $\mathrm{SSHV}_{\max }$, as can be seen in Figure 1 and Table 1. The greatest $\mathrm{SSHV}_{\text {max }}$ value $(38 \mathrm{~cm})$ of the area is on the $60^{\circ} \mathrm{W}$ section, but the best tuning $\alpha_{\max }$ and estimated maximum velocity there are significantly smaller than those in the $70^{\circ} \mathrm{W}$ section where a smaller $\operatorname{SSHV}_{\max }(33 \mathrm{~cm})$ exists. All of this information indicates that the ad hoc definition (equation (12)) of $\alpha$ is not such a constraining hypothesis as it might appear at first glance.

[16] Finally, the weak drifter-derived velocity observed on the southern jet axis of the $50^{\circ} \mathrm{W}$ section $\left(16 \mathrm{~cm} \mathrm{~s}^{-1}\right.$ compared to $42 \mathrm{~cm} \mathrm{~s}^{-1}$ on the northern jet axis) is worthy of comment. This observational information is somewhat in contradiction to the circulation schematics presented by Schmitz [1996, Figures 1-82 and 1-84], in which both axes clearly exist, but the southern one appears as the major branch feeding both a quasi-permanent anticyclonic recirculation cell just south of the Gulf Stream extension and the North Atlantic Current in the Newfoundland Basin. Our results lie between the two pictures. Further observations are necessary to clarify the mean circulation pattern of this particular region.

\subsection{Sensitivity of Solutions to Data Noise and Estimation of the Solution Error}

[17] To test the sensitivity of our best solutions to a prescribed noise of altimeter data, a Monte Carlo procedure was employed. For a Monte Carlo simulation, an artificial data set was created by adding Gaussian random noise with zero mean to the original raw data at every grid point and time step. The RMS noise level was set at $4 \mathrm{~cm}$ and the resulting corrupted data set was used to generate a new estimate of the mean velocity profile. A total of 100 Monte Carlo simulations was carried out for each of the three meridional sections across the Gulf Stream axis, using the same optimal $\alpha_{\max }$ values obtained in section 3.1. The mean standard deviation $\alpha$ of the Monte Carlo simulations for all

Table 1. SSHV $\mathrm{max}_{\max }$ and Best-Fitting $\alpha_{\max }$ at Three Longitudes Across the Gulf Stream Axis ${ }^{\mathrm{a}}$

\begin{tabular}{lccc}
\hline & $70^{\circ} \mathrm{W}$ & $60^{\circ} \mathrm{W}$ & $50^{\circ} \mathrm{W}$ \\
\hline $\mathrm{SSHV}_{\max }, \mathrm{cm}$ & 33 & 38 & 36 \\
$\alpha_{\max }$ & 0.22 & 0.17 & 0.15 \\
$\mathrm{U}_{\max }, \mathrm{cm} \mathrm{s}^{-1}$ & 52 & 38 & 31 \\
Vel. diff., $\mathrm{cm} \mathrm{s}^{-1}$ & 9.5 & 7.1 & 6.9 \\
\hline
\end{tabular}

${ }^{\mathrm{a}} \mathrm{U}_{\max }$ represents the maximum zonal velocity estimated on each meridional section using the given $\alpha_{\max }$. The last row shows the rootmean-square velocity difference between the optimal solution and drifter data for the zonal velocity profile over $5^{\circ}$ of latitude in each section. 


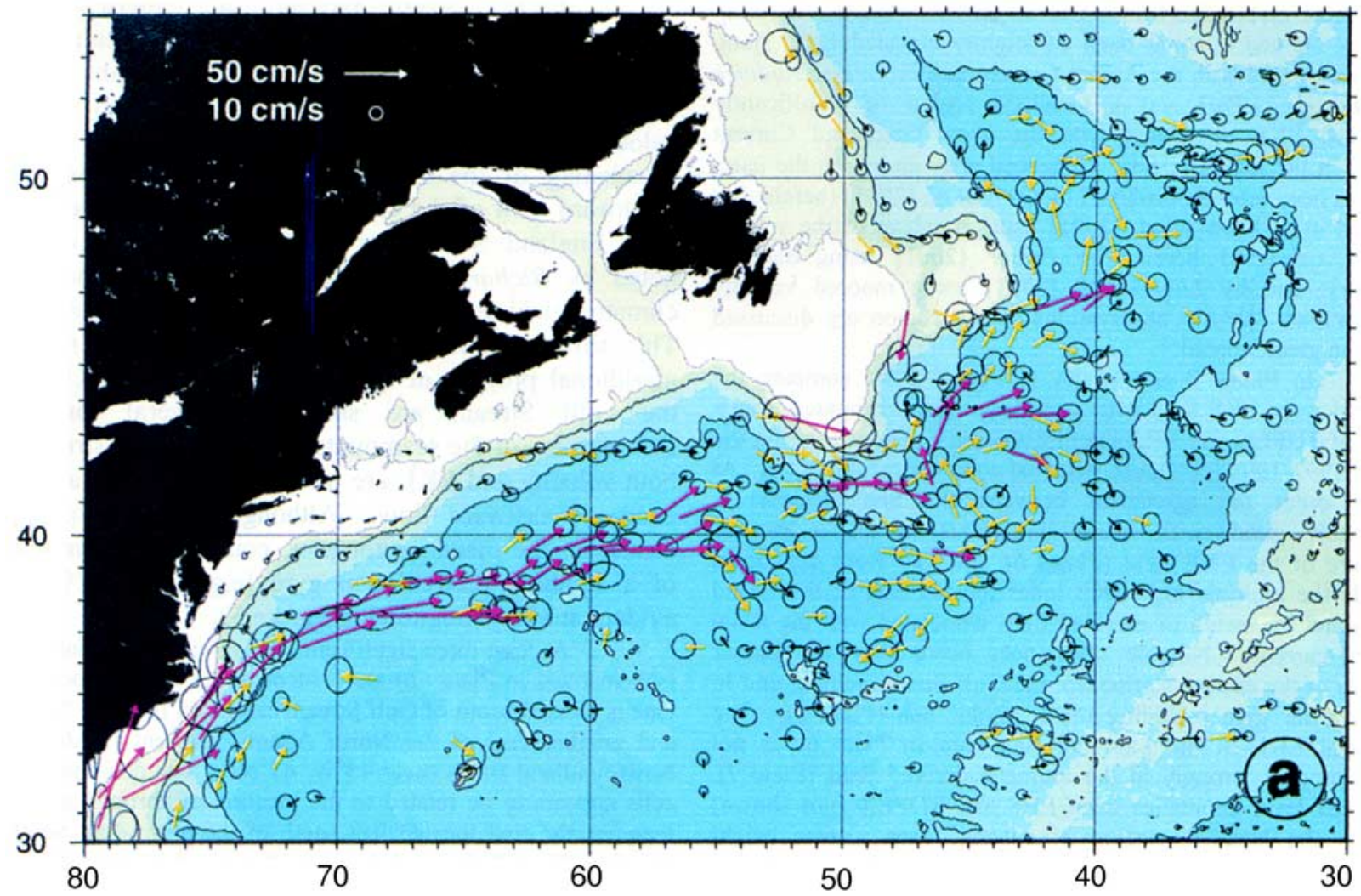

Figure 2. Drifter-derived mean velocity field in the Gulf Stream area. Red and yellow vectors indicate velocities greater than $30 \mathrm{~cm} \mathrm{~s}^{-1}$ and between 15 and $30 \mathrm{~cm} \mathrm{~s}^{-1}$, respectively. From Fratantoni [2001].

three sections is $9.0 \mathrm{~cm} \mathrm{~s}^{-1}$, while the mean absolute bias between the original solutions and the mean solutions from the Monte Carlo simulations is $0.1 \mathrm{~cm} \mathrm{~s}^{-1}$. This latter value is negligible compared with the standard error $(=\sigma / \sqrt{100})$ of $0.9 \mathrm{~cm} \mathrm{~s}^{-1}$, indicating that there is no significant difference for the mean between the results from the original data and those from the noise-added data. On the other hand, the mean standard deviation $\left(9.0 \mathrm{~cm} \mathrm{~s}^{-1}\right)$ may serve as a measure of the overall solution uncertainty (error) due to altimeter data noise. This error estimate is compatible with the RMS misfits ( 6.9 to $9.5 \mathrm{~cm} \mathrm{~s}^{-1}$ ) between the optimal velocity profiles and the drift-derived velocity profiles mentioned in section 3.1. There we have shown that a $10 \%$ change in $\alpha_{\max }$ yields a few $\mathrm{cm} \mathrm{s}^{-1}$ change in velocity. We propose therefore a somewhat conservative error of $10 \mathrm{~cm} \mathrm{~s}^{-1}$ for our solution, to allow for some flexibility in the choice of the best-fitting $\alpha_{\max }$.

\subsection{Mean Current Field of the Gulf Stream Area}

[18] We have shown that the Method actually works by reproducing reasonably well the meridional profiles of zonal velocity across the Gulf Stream axis. We will test here whether the Method works also for the mean velocity field of the entire Gulf Stream area. The drifter-derived mean velocity field of Fratantoni [2001] presented in Figure 2 is used as a reference. Similar calculational procedures as already described have been applied, together with following provisions. First, the zonal direction of the mean velocity is set eastward everywhere except for several westward branches clearly seen in the drifter data of
Figure 2. Those westward flow regions include, in particular, a zonal band near $37^{\circ} \mathrm{N}$ between $56^{\circ} \mathrm{W}$ and $40^{\circ} \mathrm{W}$ just north of the Corner Rise, another zonal band near $34^{\circ} \mathrm{N}$ between $64^{\circ} \mathrm{W}$ and $59^{\circ} \mathrm{W}$, the southern end of the Newfoundland Basin, and the northeastern corner of the Grand Banks close to the $4000-\mathrm{m}$ isobath between $47^{\circ} \mathrm{N}$ and $50^{\circ} \mathrm{N}$ and west of $41^{\circ} \mathrm{W}$. Second, results over the shallow shelf of depths less than $200 \mathrm{~m}$ and the continental boundary regions west of $74^{\circ} \mathrm{W}$ are not presented for the reasons explained in section 2.4. Last, but most importantly, we use $\alpha_{\max }=0.18$ as the unique parameter representing the whole study area. This value is the mean of optimal $\alpha_{\max }$ values obtained from the test on the three meridional sections across the Gulf Stream axis. One might prefer using different $\alpha_{\max }$ for different longitudes, as resulted from that test, as for example, $\alpha_{\max }=0.15$ for the region east of $50^{\circ} \mathrm{W} ; \alpha_{\max }=0.16$ for the region between $50^{\circ} \mathrm{W}$ and $60^{\circ} \mathrm{W}, \alpha_{\max }=0.20$ for the region between $60^{\circ} \mathrm{W}$ and $70^{\circ} \mathrm{W}$, and $\alpha_{\text {max }}=0.22$ for the region west of $70^{\circ} \mathrm{W}$. This would certainly yield local velocities a little closer to the drifter data, but our objective is to demonstrate that a similar velocity field can be obtained using a single adequately chosen $\alpha_{\max }$ value for the entire area. A refinement of the solution should be possible with better knowledge of the long-term mean velocity field, but that has to be left for future investigations.

[19] The altimeter-derived mean velocity field in the Gulf Stream area is shown in Figure 3, which compares well with the drifter-derived field of Figure 2. There is a high level of coherency between the two maps, both in direction and magnitude of velocity vectors. Note that our time-mean 

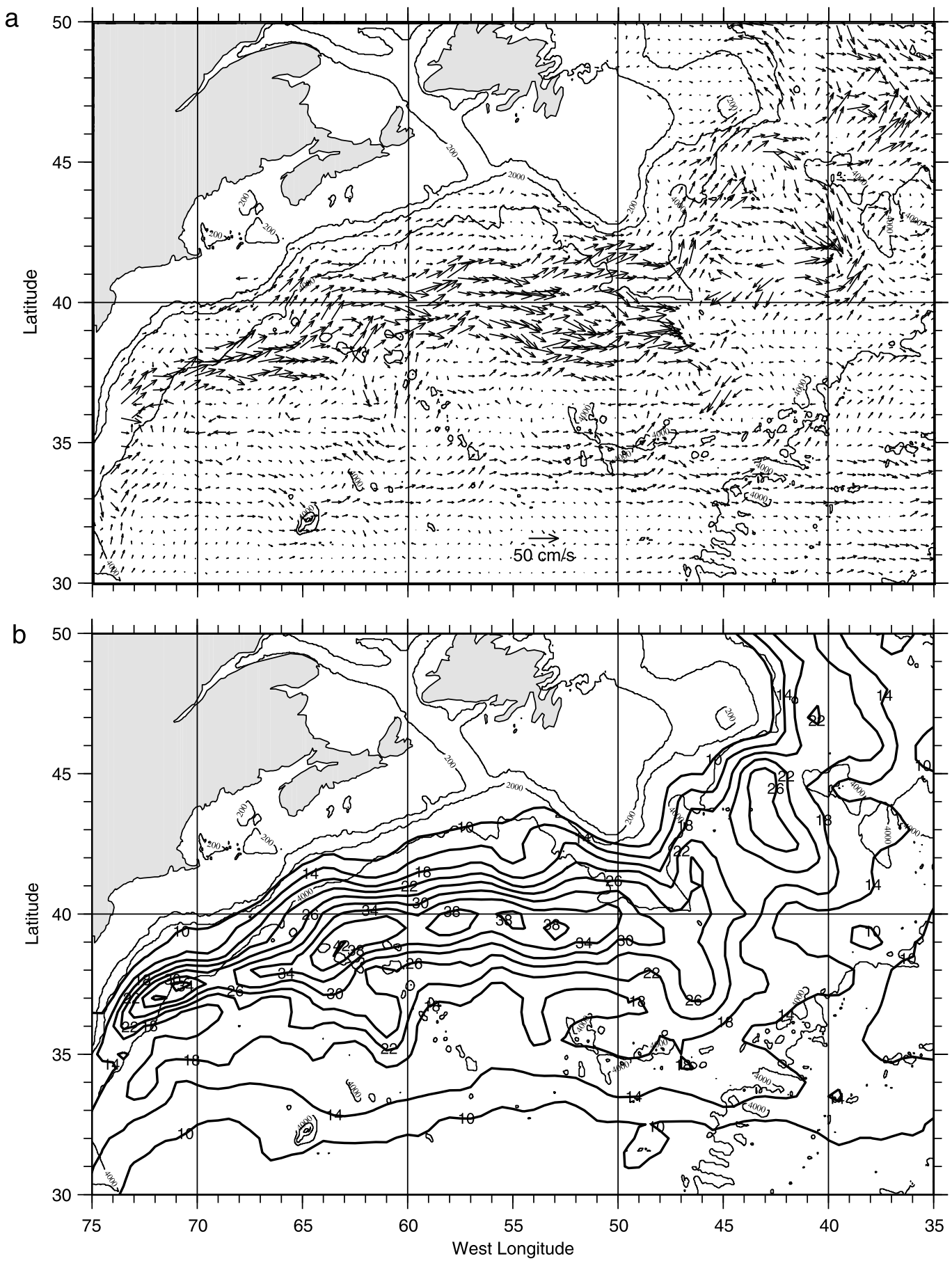

Figure 3. (a) Time-mean velocity field estimated from the merged TOPEX/Poseidon-ERS data in the Gulf Stream area. Vectors are every $0.5^{\circ}$ in latitude and longitude. (b) Sea surface height variability in centimeters, defined as root-mean-square variability of $\eta^{\prime}$ over 5.3 years between April 1995 and August 2000 .

velocities along the Gulf Stream axis are mostly 30 $60 \mathrm{~cm} \mathrm{~s}^{-1}$, with a maximum of $73 \mathrm{~cm} \mathrm{~s}^{-1}$, in fair agreement with drifter observations. Fratantoni [2001] previously noted several distinguishing features of the Gulf Stream, namely: a step-like northward jump in the latitude of maximum eastward velocity just north of the New England Seamounts (near $63^{\circ} \mathrm{W}, 38^{\circ} \mathrm{N}$ ); a widening of the stream with more energetic eastward flow downstream of the seamounts; and evidence for three significant anticyclonic recirculation cells, one located south of the Gulf Stream extension (near $50^{\circ} \mathrm{W}, 38^{\circ} \mathrm{N}$ ), another in the southern Newfoundland Basin (near $44^{\circ} \mathrm{W}, 42^{\circ} \mathrm{N}$ ), and the third in the northern Newfoundland Basin (near $40^{\circ} \mathrm{W}, 49^{\circ} \mathrm{N}$ ). Most of these observed features are nicely reproduced with correct locations in our mean velocity field, confirming also that they are quasi-permanent circulation features. Another noticeable feature seen on both maps is that the Gulf Stream extension east of $52^{\circ} \mathrm{W}$ is separated into two branches and 
that the northern one passes across the protruding Southeast Newfoundland Ridge. After crossing the ridge, the branch extends northward along the 4000-m isobath, forming the North Atlantic Current. Finally, our map shows a zonal band of moderate velocity eastward flow just south of the Corner Rise near $34^{\circ} \mathrm{N}$, which extends beyond $35^{\circ} \mathrm{W}$ across the Mid-Atlantic Ridge. Figure 2 hints also at this eastward flow, which, according to Fratantoni's schematic (his Plate 6), corresponds to the upstream flow of the Azores Current.

\section{Application of the Method to the Crozet Basin}

[20] The Crozet Basin is also an interesting site for further testing the Method. The frontal zone of the basin forms the major passage of the ACC that is quasi-permanently juxtaposed to the Agulhas Return Current extension, creating one of the most intensified frontal zones of the Southern Ocean [Park et al., 1993]. Also, strong eddy activity associated with powerful mesoscale meanders and eddies is omnipresent there [Park and Saint-Guily, 1992; Park and Gambéroni, 1995; Park et al., 1993, 2002]. During the recent Antares-4 cruise, fine-grid current measurements across this frontal zone were made using an acoustic Doppler current profiler (ADCP) in JanuaryFebruary 1999 [Park et al., 2002]. We use this one-time survey as a reference for estimating the mean and total (mean plus eddy) velocity fields of the area. The calculational procedures here are a little different from the Gulf Stream case, because we have information on instantaneous total currents only, without any quantitative information on the mean velocity field. The strategy we have adopted is as follows: First, the eddy velocity field for the central period of the cruise is calculated using equation (5). Second, an estimation of the mean velocity field is made using a first guess of $\alpha_{\max }$, say 0.1 . The zonal direction of mean velocity is set eastward at all grid points, as we have no information on the existence of westward streams in the study area. Third, the total velocity field is obtained by adding the eddy and mean fields, the results of which are then compared with the ADCP measurements. We repeat the second and third steps by tuning $\alpha_{\max }$ until we obtain the least RMS difference between total velocity estimates and ADCP velocities within the fine-grid survey region. In practice, the tuning is done by iteration, successively incrementing $\alpha_{\max }$ by 0.01 . We have obtained in this way the best tuning parameter $\alpha_{\max }=0.13$. First of all, we present and discuss the mean velocity field of the Crozet Basin obtained using this $\alpha_{\max }$ value, followed by the total velocity field during the Antares- 4 cruise. Details of the comparison between the estimated total velocity field and ADCP measurements are given in section 4.3 .

\subsection{Mean Velocity Field of the Crozet Basin}

[21] The calculated mean velocity field of the Crozet Basin is shown in Figure $4 \mathrm{a}$, together with the map of $\mathrm{SSHV}$ in Figure $4 \mathrm{~b}$. In the latitude band of $41^{\circ} \mathrm{S}-47^{\circ} \mathrm{S}$, there appears a near-zonal band of strong currents (up to $51 \mathrm{~cm} \mathrm{~s}^{-1}$ ) centered at $42^{\circ} \mathrm{S}$ at the entrance to the Crozet Basin near $50^{\circ} \mathrm{E}$, gradually shifting southward toward the east as far as the central basin at $\sim 60^{\circ} \mathrm{E}$, then hugging the northern escarpment of the Kerguelen Plateau along $45^{\circ} \mathrm{S}-$ $46^{\circ} \mathrm{S}$. This current band corresponds to the well-known Crozet Basin frontal zone, one of the strongest hydrographic frontal zones in the Southern Ocean [Park et al., 1993], indicating that the feature represents the quasi-permanent surface circulation of the area. Outside this quasi-zonal concentrated flow, several branches of weaker eastward flow appear north of the frontal zone. To the south of the frontal zone where the SSHV is least, the flow is both weak and featureless. This is also consistent with previous hydrographic work which indicates weak baroclinic currents in the area [Park et al., 1993; Park and Gambéroni, 1997].

[22] Qualitatively, the present solution is quite similar to the dynamic topography of Park and Gambéroni [1995] or that from climatology [Levitus and Boyer, 1994; Levitus et al., 1994], especially in terms of geographical positions of the jet. Quantitatively, however, there is a large difference in that the jet strength is up to three times stronger in the present solution than from climatology. Feron et al. [1998] propose an improved dynamic topography from altimetry, giving a maximum zonal velocity of $20 \mathrm{~cm} \mathrm{~s}^{-1}$ at $54.5^{\circ} \mathrm{E}$. This current core is also significantly weaker and shifted farther northward [Feron et al., 1998, Figure 2d], compared with our solution. With regard to the jet, our solution compares more favorably with the dynamic topography from the Gaussian jet model of Gille [1994]. A more detailed and extensive comparison is necessary for better evaluating the relative performance of each method. However, it might be worth mentioning at this stage that Feron et al. [1998] need no tuning and no a priori information on the flow direction, while Gille [1994] and the Method do.

\subsection{Total Velocity Field of the Crozet Basin During the Antares-4 Cruise}

[23] To reproduce the instantaneous total velocity field, the time-mean velocity field is added to the time-variable field that can be readily calculated at any given time using equation (5). Figure 5a shows such a snapshot on 29 January 1999, the central period of the Antares-4 fine-grid survey that was made within a limited region centered at $44^{\circ} 30^{\prime} \mathrm{S}$, $63^{\circ} \mathrm{E}$ (marked by the small parallelogram). This total velocity field can be compared with the monthly composite satellite images of SeaWiFS-derived chlorophyll concentrations and Advanced Very High Resolution Radiometer (AVHRR) derived sea surface isotherms in February 1999 (Figure 5b). Also indicated on the latter map are trajectories of two satellite-tracked subsurface buoys (dashed lines) launched at the beginning of the fine-grid survey. Hydrographic fronts represented by selected isotherms (thick lines) depict the major streams of the area, which are composed of the Agulhas Front (AF) associated with the Agulhas Return Current extension and the tightly merged Subtropical Front (STF) and Subantarctic Front (SAF), which mark the concentrated ACC [Park et al., 2002]. All these satellite images from completely independent sources are coherent and reveal useful information on all scales of motion in the regional current field, from large to mesoscale, such as swift streams, developing meanders, intrusion, and detached isolated eddies. Our total velocity field with a maximum velocity up to $103 \mathrm{~cm} \mathrm{~s}^{-1}$ (Figure 5a) is in good agreement with these images. Our calculations indicate also that the time-mean field (Figure 4a) represents mainly the quasi-permanent flow associated with the ACC 
a

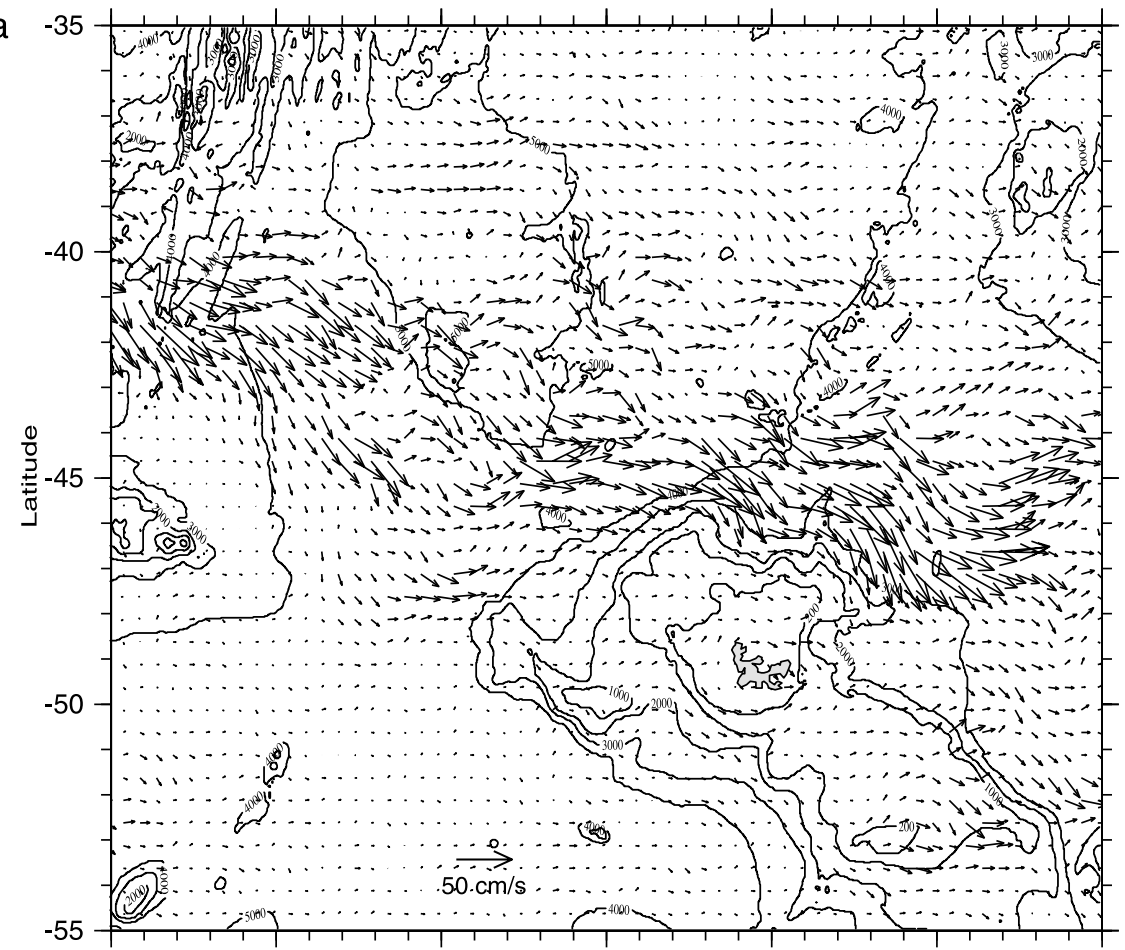

b

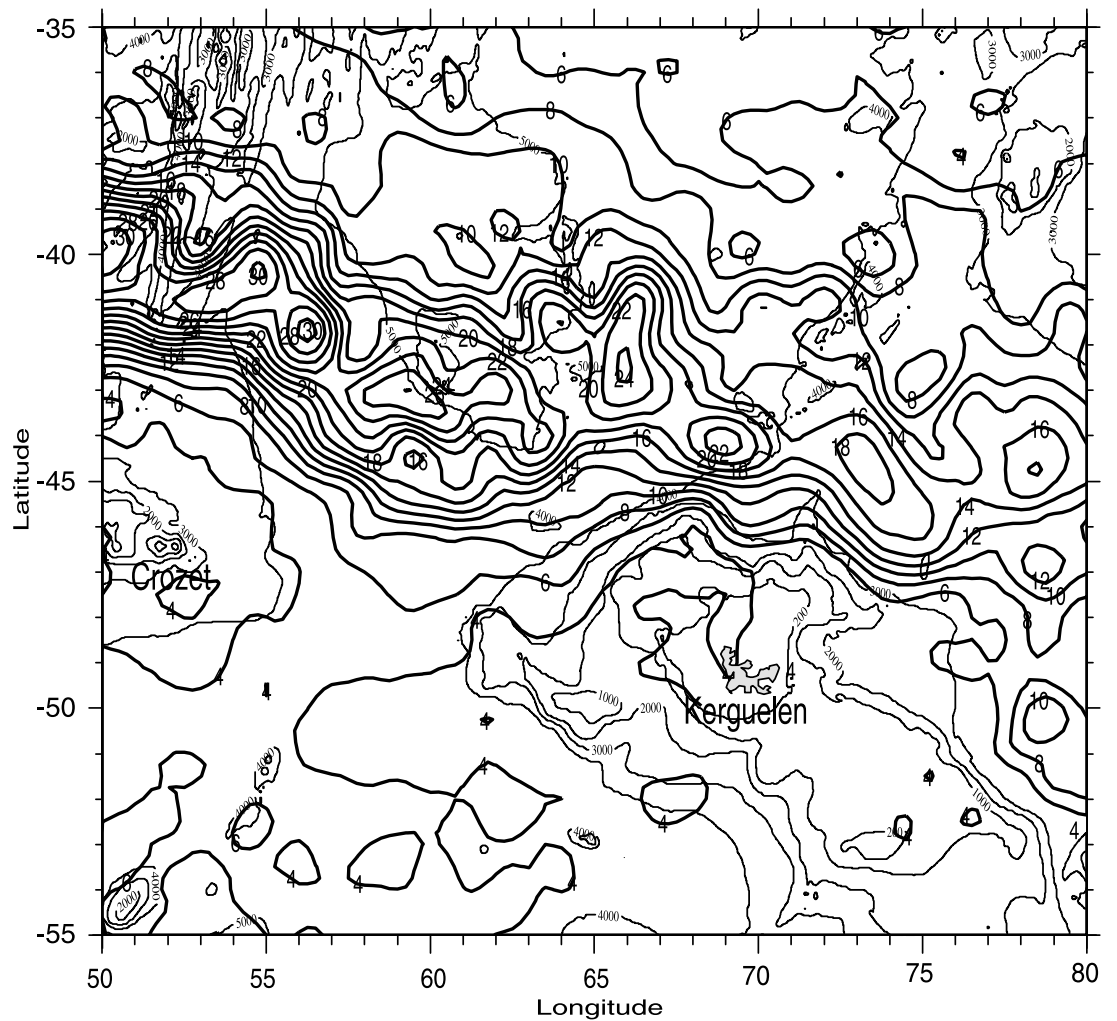

Figure 4. Same as Figure 3, for the Crozet Basin area.

transiting the Crozet Basin, while just north of this current is the time-variable highly meandering Agulhas Return Current, creating intense eddy activity. South of the frontal zone, however, no comparable eddy activity exists (see also Figure 4b). Although its governing dynamics are not well understood, this asymmetric eddy activity across the Crozet
Basin frontal zone has been recognized for some time and is considered a major contributor to the exchanges of subantarctic and subtropical water masses [Park et al., 1993; Park and Gambéroni, 1997; Park et al., 2002].

[24] Figure 6a shows the ADCP-derived velocity vectors at $100 \mathrm{~m}$ depth along the cruise tracks of the entire Antares- 

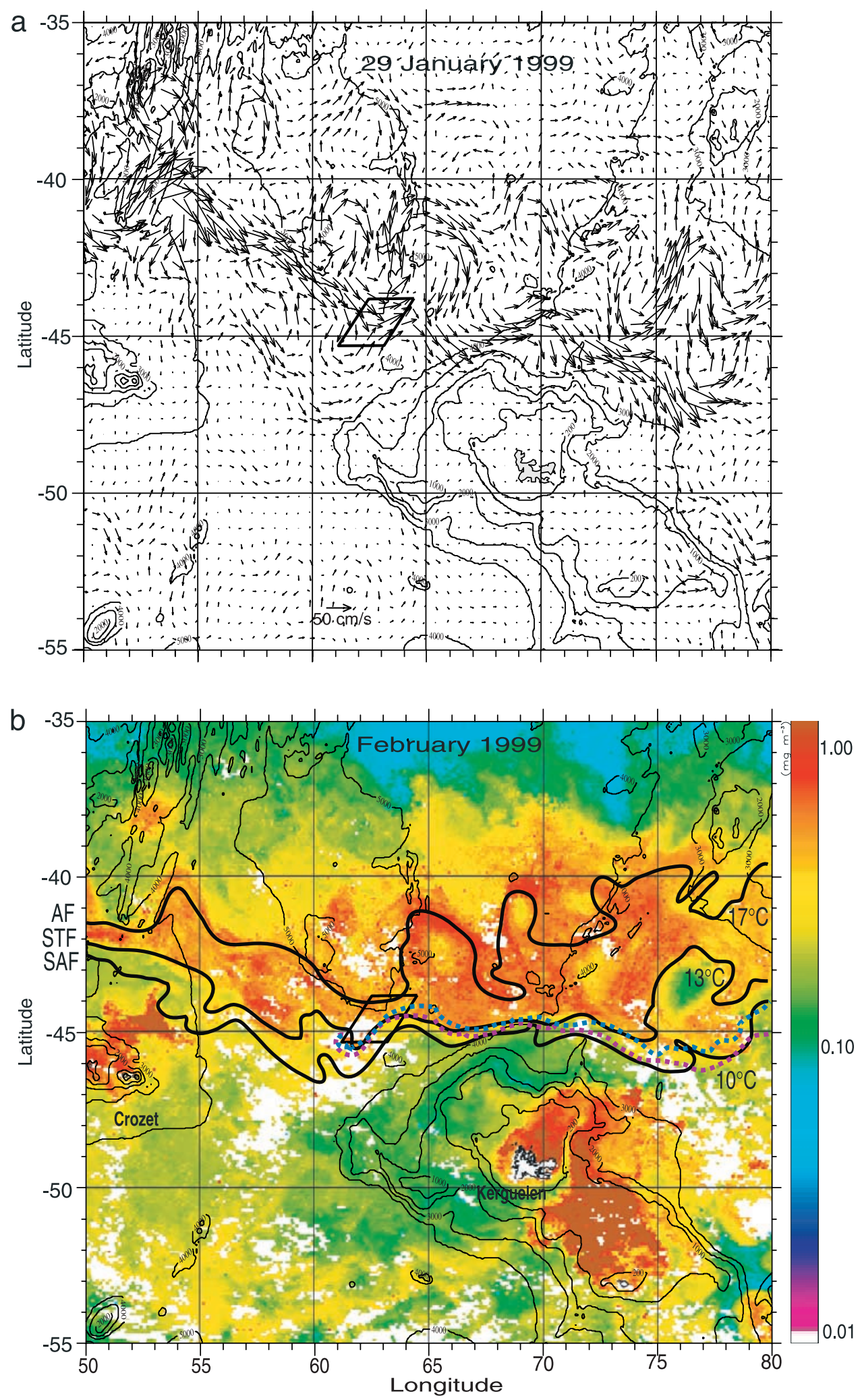

Figure 5. (a) Total (mean plus eddy) velocity field estimated for 29 February 1999 from the merged TOPEX/Poseidon-ERS data. Vectors are every $0.5^{\circ}$ in latitude and longitude. The small parallelogram in the central basin represents the fine-grid survey region. (b) Monthly composite of SeaWiFS chlorophyll images for February 1999, superimposed on which are the Advanced Very High Resolution Radiometer isotherms $17^{\circ}, 13^{\circ}$, and $10^{\circ} \mathrm{C}$ representing, respectively, the Agulhas Front (AF), the Subtropical Front (STF), and the Subantarctic Front (SAF). Trajectories of two subsurface buoys (dashed lines) satellitetracked in January-February 1999 are indicated. Reprinted from Park et al. [2002] with permission from Elsevier Science. 

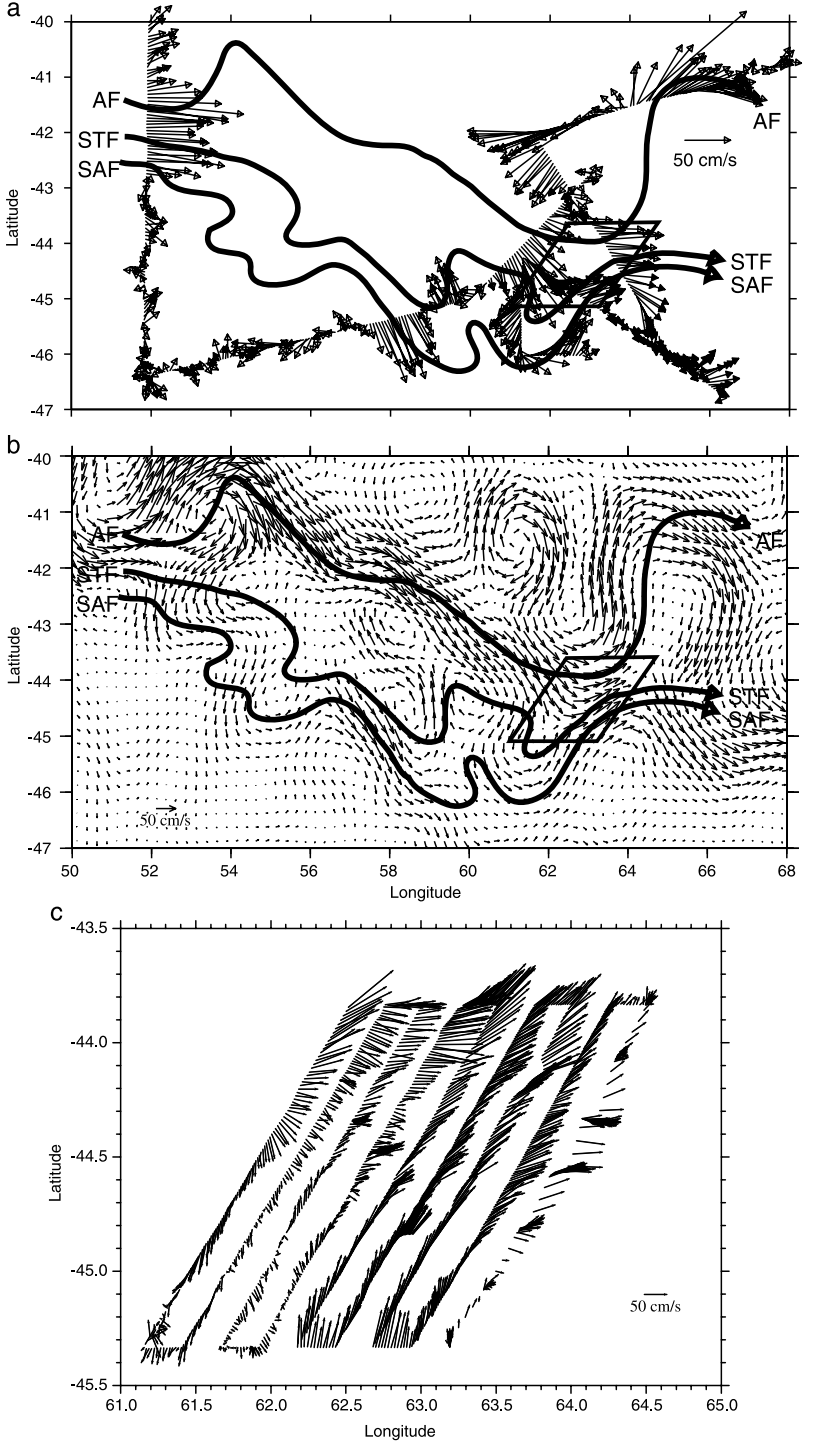

Figure 6. (a) Acoustic Doppler current profiler (ADCP) currents at $100 \mathrm{~m}$ depth along the entire Antares-4 cruise tracks made over 40 days between 12 January and 20 February 1999 , with the three fronts of Figure $5 \mathrm{~b}$ superimposed. (b) Zoom of the calculated total velocity field on 29 February 1999 shown in Figure 5a. Vectors are every $0.25^{\circ}$ in latitude and longitude. (c) ADCP currents at $100 \mathrm{~m}$ depth during the 14 days of the fine-grid survey between 22 January and 5 February 1999. Figures $6 \mathrm{a}$ and $6 \mathrm{c}$ are reprinted from Park et al. [2002] with permission from Elsevier Science.

4 campaign (12 January to 20 February 1999), compared to our total velocity field in the same area on 29 January 1999 (Figure $6 \mathrm{~b}$ ), corresponding to the central period of the finegrid ADCP measurements made during the period of 22 January to 5 February 1999 (Figure 6c). A remarkable similarity is observed between the calculated and measured velocity fields, although the measurements are not synoptic. The anticyclonic Agulhas Return Current (or AF) and the cyclonic bend in the ACC (or merged STF and SAF) within the fine grid are also correctly diagnosed. Some minor frontal shifts in comparison with velocity vectors are noticed, especially along the AF that is mostly associated with the strongest eddy activity. This suggests that nonsynopticity between the different fields, in the presence of time-variable intense mesoscale eddies, is probably the major cause of the shifts.

\subsection{Calibration and Error Estimate}

[25] The fine-grid ADCP measurements (Figure 6c) have been used to calibrate our velocity estimates from altimetry. To this end, the fine-grid measurements made with an along-track resolution of a few kilometers were optimally interpolated onto the T/P-ERS grid. The measured velocities were quite strong, mostly ranging from 40 to $100 \mathrm{~cm} \mathrm{~s}^{-1}$, except for the relatively quiescent southwestern quarter of the fine grid. Our calibration has been based on statistics in a region bounded by $62.5^{\circ} \mathrm{E}-63.5^{\circ} \mathrm{E}$ and $44.5^{\circ} \mathrm{S}-45.0^{\circ} \mathrm{S}$ where well-defined concentrated hydrographic fronts coincided nicely with the strong ADCP velocity field. The mean ADCP velocity vector of this region was compared with a series of total velocity vectors calculated from altimetry. These latter vectors were obtained by summing the instantaneous eddy velocity vector on 29 January and time-mean velocity vectors calculated with different values of $\alpha_{\max }$. This comparison yielded the best-fitting coefficient $\alpha_{\max }=$ 0.13 for the altimeter-derived time-mean velocity field we have described. The mean difference between the calculated total velocity vectors and the ADCP measurements is $11.6 \mathrm{~cm} \mathrm{~s}^{-1}$ for the speed and $11^{\circ}$ for the direction. This mismatch in speed is close to the mean solution error $\left(10 \mathrm{~cm} \mathrm{~s}^{-1}\right)$ estimated in the Gulf Stream area in section 3.2.

[26] Within the limited test region, the total velocity vectors $(u, v)$ from altimetry are averaged to $(43.7,19.4)$ $\mathrm{cm} \mathrm{s}^{-1}$, while the corresponding ADCP vectors are averaged to $(43.8,31.0) \mathrm{cm} \mathrm{s}^{-1}$. Compared with the ADCP measurements, the relative misfit of our solution amounts to $20 \%$, a value that we tentatively propose as the relative error of a velocity estimation. If geostrophic velocities from Levitus climatology replace the time-mean velocity vectors from altimetry, the relative error becomes far greater $(51 \%)$ because of the highly underestimated geostrophic velocities from climatology yielding a time-mean velocity of (15.1, $0.6) \mathrm{cm} \mathrm{s}^{-1}$, compared to $(39.0,2.2) \mathrm{cm} \mathrm{s}^{-1}$ from altimetry. In the test region, the altimeter-derived eddy velocities during the survey period were relatively weak and averaged to $(4.7,17.2) \mathrm{cm} \mathrm{s}^{-1}$. This leads to a further degraded performance $(77 \%$ error) when the comparison is made between the ADCP data and calculated eddy velocities only (i.e., when the time-mean velocities from altimetry are not taken into account).

[27] In summary, our Method permits one to get a realistic surface velocity field from altimetry, as long as adequate information on regional velocity statistics is available. Some uncertainty of the solution is inevitable due probably to the necessary approximations of the Method and to errors in the altimeter data themselves. Some aspects of the latter problem have already been discussed in section 2, and we give below a short comment on the high-frequency aliasing problem of altimeter data.

[28] As pointed out by a number of recent studies [Fukumori et al., 1998; Stammer et al., 2000; Tierney et $a l ., 2000]$, there are energetic high-frequency ocean signals 


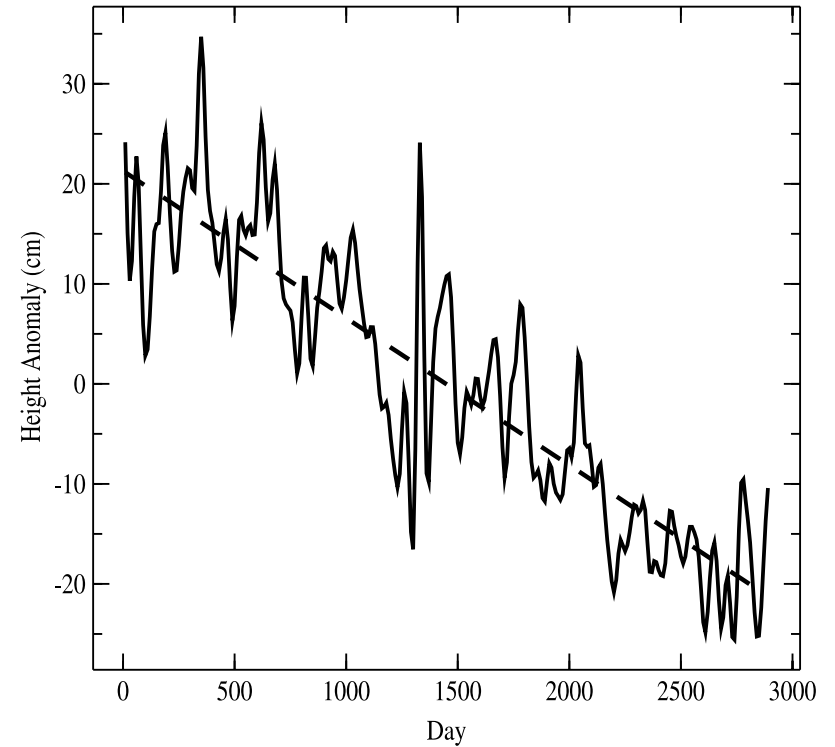

Figure 7. OCCAM sea surface height time series at $46^{\circ} \mathrm{S}$, $57^{\circ} \mathrm{E}$, showing an abnormal drift in model sea level (dashed line).

(with periods shorter than 20 days), particularly in the Southern Ocean, that cannot be resolved by the 10-day $\mathrm{T} / \mathrm{P}$ orbiting period, but are likely to be aliased in the altimetric time series. Stammer et al. [2000] and Tierney et al. [2000] propose a significant reduction of the aliased sea level variance using a sophisticated ocean circulation model. However, the implementation of reliable modelbased corrections of altimeter data seems to be premature [Chelton et al., 2001]. The results of Fukumori et al. [1998] suggest a potential contamination due to aliasing by up to $3 \mathrm{~cm}$ in our study area, which corresponds to about $50 \%$ of the variance for our SSHV of $4 \mathrm{~cm}, 25 \%$ for SSHV of $6 \mathrm{~cm}$, and less than $10 \%$ for SSHV greater than $10 \mathrm{~cm}$. This suggests that only the area surrounding the Crozet Basin frontal zone where SSHV is much greater than $6 \mathrm{~cm}$ may be relatively free of the aliasing problem.

\section{Discussion}

[29] Despite the favorable test results of our calculations against the best available velocity measurements in two well-known areas, one would like to further check the performance of the Method against a numerical model. With this in mind, we have obtained model SSH data for the Crozet Basin for the last 8 years of a prognostic run of the OCCAM global ocean model. A. C. Coward of the Southampton Oceanography Centre, UK, has kindly communicated these data. OCCAM is a free surface model run on a $0.25^{\circ}$ grid and forced with 6-hourly European Centre for Medium-Range Weather Forecasting (ECMWF) wind stresses (1992-2000), with surface relaxation of temperature to monthly Reynolds sea surface temperatures and surface salinity to monthly Levitus fields (A. C. Coward, personal communication, 2003). The output furnishes 5-day mean fields produced every 5 model days. We resampled the data over 10-day intervals so as to have the same temporal resolution as the altimeter data.
[30] Before applying the Method, we checked several time series of the OCCAM SSH at different grid points to discover to our great surprise that the mean sea level changes appreciably with time. An example is given in Figure 7 , which shows a sea level fall at $46^{\circ} \mathrm{S}, 57^{\circ} \mathrm{E}$ as much as $43 \mathrm{~cm}$ over 8 years, equivalent to an SSH trend of $-5.4 \mathrm{~cm} \mathrm{yr}^{-1}$. This value is an order of magnitude greater than that observed from altimetry [Park, 2001] and in the opposite sense. This example is not an exception but represents rather a general feature of the OCCAM output we used. Such a drift should be an artifact inherent in many global models (A. C. Coward, personal communication, 2003) probably because of inaccurate modelization of certain processes, as, for example, the production of insufficient quantities of Antarctic Bottom Water (D. J. Webb et al., unpublished document, 1998). In this case the SSH anomaly $\eta^{\prime}$ defined as deviations from the time-mean SSH should have two components: a high-frequency component $\widetilde{\eta}^{\prime}$ likely associated with mesoscale eddy activity and a linear trend component associated with the unrealistic model drift, such as

$$
\eta^{\prime}=\widetilde{\eta}^{\prime}+\delta\left(t-t_{0}\right)
$$

where $\delta(x, y)$ is the trend coefficient and $t_{0}$ is the middle point of the data length. Because of the presence of the undesired drift, the OCCAM SSH data cannot be directly injected into our Method, except for the case where $\delta$ is spatially homogeneous within a given study area. Then the spatial gradient of $\delta$ disappears, so the presence of the common trend may not affect the solution, enabling one to remove that trend from the original $\mathrm{SSH}$ field. Such an ideal case is not observed, and the $\delta$ field of our Crozet Basin area shown in Figure 8 is highly heterogeneous, with $\delta$ values varying from $+1.2 \mathrm{~cm} \mathrm{yr}^{-1}$ to $-7.5 \mathrm{~cm} \mathrm{yr}^{-1}$, although negative trends are dominant. Also, there appears in that field a structured mesoscale pattern, with a typical zonal wavelength of $400-500 \mathrm{~km}$. Consequently, the OCCAM SSH output was found to be far from perfect, contrary to what we had hoped.

[31] What might happen if we voluntarily remove individual trends having such a heterogeneous distribution,

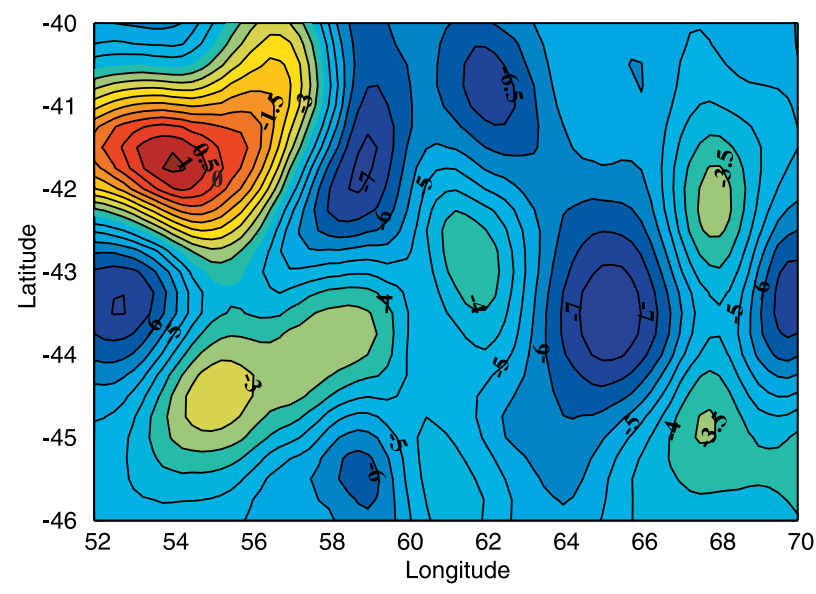

Figure 8. Map showing the OCCAM sea surface height trends in the Crozet Basin area. Units are $\mathrm{cm} \mathrm{yr}^{-1}$. 

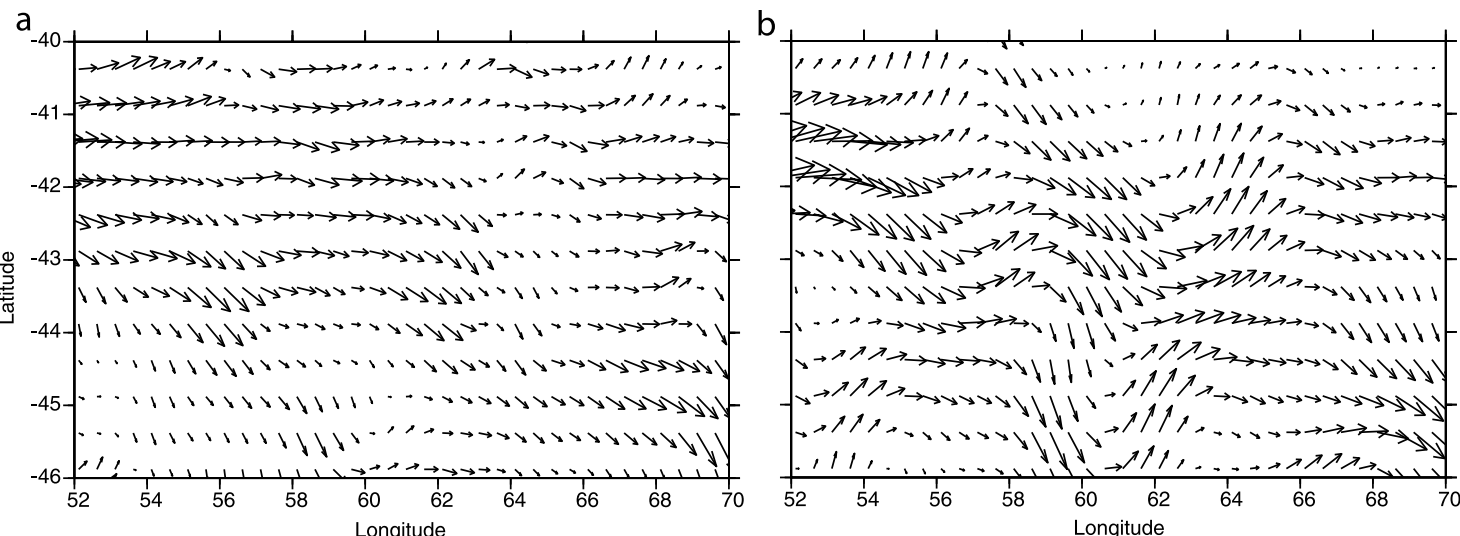

Figure 9. (a) Time-mean velocity field in the Crozet Basin area estimated from the OCCAM sea surface height (SSH) output. Before applying the Method, the abnormal SSH drift omnipresent in the OCCAM output had been eliminated. (b) Time-mean geostrophic velocity field given by OCCAM. The maximum vector magnitude is $50 \mathrm{~cm} \mathrm{~s}^{-1}$.

despite the apparent inadequacy of the OCCAM SSH for testing the Method? Such a trial was made, and the resultant SSH anomaly field was used as input data for our Method. A similar calculational procedure as outlined in sections 2 and 3 was applied. The resulting best solution of the time-mean velocity field in the Crozet Basin area is shown in Figure 9, compared to the OCCAM time-mean geostrophic velocity field. The large-scale circulation pattern is similar in both fields, with the strongest zonal currents concentrating between $41^{\circ} \mathrm{S}$ and $43^{\circ} \mathrm{S}$ at the entrance to the basin at $52^{\circ} \mathrm{E}$, shifting gradually southward and then leaving the basin at $70^{\circ} \mathrm{E}$ between $44^{\circ} \mathrm{S}$ and $46^{\circ} \mathrm{S}$. Apart from this, our solution is quite different from the OCCAM velocity vectors, especially for the meridional component of currents. In the OCCAM velocity field a mesoscale wave-like feature accompanied with alternating northward and southward currents is most noticeable, which is nearly completely absent in our solution. The overall RMS velocity vector difference between the two is $12 \mathrm{~cm} \mathrm{~s}^{-1}$, most of which is attributable to differences in meridional velocity. Figure 10a shows the velocity difference (OCCAM minus Method) field. Note that the alternating northward and southward currents of this field have some relationship with the mesoscale topography of the $\delta$ field (see Figure 8), suggesting that these two fields may not be independent.

[32] To address the possibility of a role played by the $\delta$ field for the wave-like meridional currents seen in the OCCAM field, we put $\delta$ as

$$
\delta=\frac{\partial \hat{\eta}^{\prime}}{\partial t}
$$

where $\hat{\eta}^{\prime}(x, y, t)$ is the $\mathrm{SSH}$ anomalies associated with the heterogeneous trend field $\delta(x, y)$ that is not taken into account by our Method. Partial differentiating equation (17) in $x$ and $y$, and applying the geostrophic relationship, we obtain

$$
\begin{gathered}
\frac{g}{f} \frac{\partial \delta}{\partial x}=\frac{\partial}{\partial t}\left(\frac{g}{f} \frac{\partial \hat{\eta}^{\prime}}{\partial x}\right)=\frac{\partial \hat{v}}{\partial t} \\
-\frac{g}{f} \frac{\partial \delta}{\partial y}=\frac{\partial}{\partial t}\left(-\frac{g}{f} \frac{\partial \hat{\eta}^{\prime}}{\partial y}\right)=\frac{\partial \hat{u}}{\partial t} .
\end{gathered}
$$

[33] These equations show that the presence of the heterogeneous $\delta$ field implies, by geostrophy, a constant velocity vector tendency $(\partial \hat{u} / \partial t, \partial \hat{v} / \partial t)$ at each grid point. It is thus
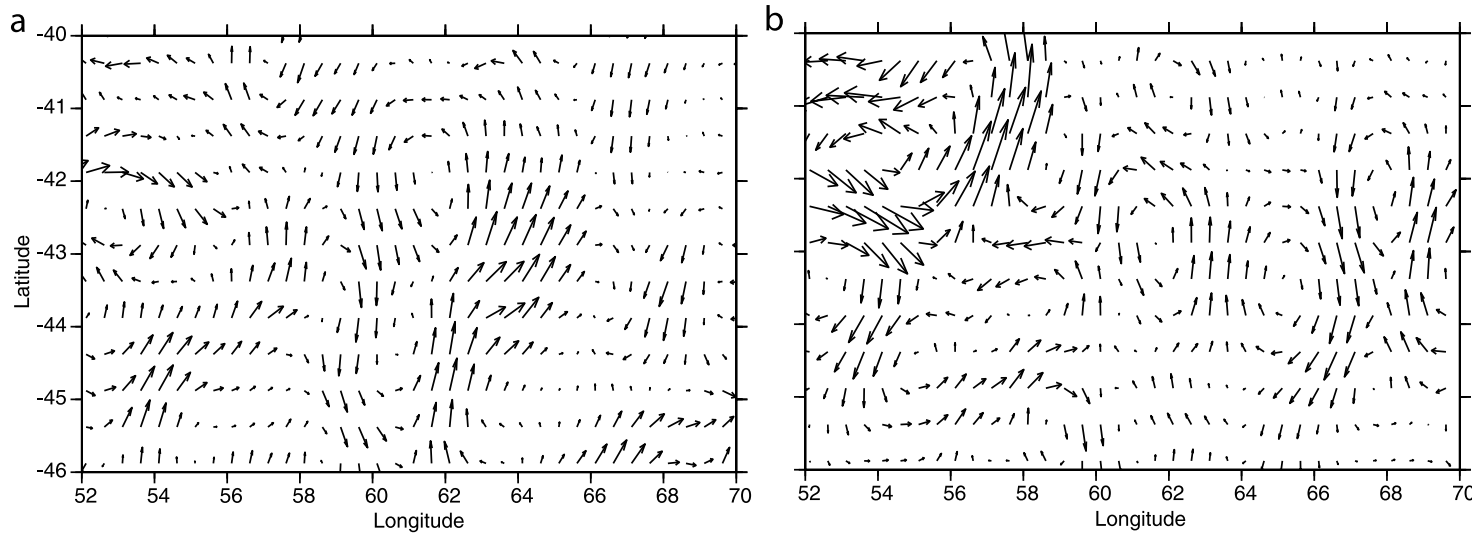

Figure 10. (a) Velocity difference field between OCCAM and the Method. (b) OCCAM velocity tendency field arising from the model sea surface height drift. This field is calculated from equations (18) and (19). Units are arbitrary. 
expected that the instantaneous OCCAM velocity vector at each grid point is likely to be under constant influence of such a velocity tendency, in addition to other dominant constraints of the model. This tendency field estimated from equations (18) and (19) is shown in Figure 10b, which reveals in many places some similarity with the velocity difference field (Figure 10a). We conclude that a substantial part of velocity differences between OCCAM and the Method can be attributed to the abnormal drift existing in the OCCAM SSH. However, the present test is inconclusive concerning the central question of how well the Method works in comparison with a "perfect" SSH field from a numerical model. Such a perfect field might be obtained from a finely resolved, free surface global model similar to OCCAM but having a negligible SSH drift with time. A further test with such a perfect model output, if it exists at all, is left for a future study.

\section{Concluding Remarks}

[34] The boundary condition at the free surface provides a new estimate of the unknown time-mean velocity field from satellite altimetry. If scaled adequately, this condition becomes an algebraically manageable equation with two unknowns $(\bar{u}, \bar{v})$ and an adjustable parameter $\alpha_{\max }$. When applied for each altimeter time step, this becomes a highly overdetermined system which can be solved by classical least squares. If precise information on the velocity statistics of the study area was available, the parameter $\alpha_{\max }$ could be refined by an iterative fitting method. Even though we do not know exactly the regional velocity statistics, experience shows that with $\alpha_{\max }$ between 0.13 and 0.18 , qualitatively reasonable results can be obtained for strong current areas of eddy activity comparable to those in the Crozet Basin and the Gulf Stream. Owing to inherent errors in altimeter data possibly leading to a solution error of $10 \mathrm{~cm} \mathrm{~s}^{-1}$ (see section 3.2) and the spatial resolution problem associated with the merged T/P-ERS data, however, the present Method may not be useful for regions of weak currents or for narrow boundary currents close to coasts. Within these limitations, we have demonstrated that our new Method opens up the possibility of getting a realistic surface velocity field for major ocean current systems, even before the advent of a precise geoid.

[35] The present Method yields results somewhat comparable to those from the Gaussian jet model [Kelly and Gille, 1990; Gille, 1994], which is not surprising because both methods use information on eddy statistics in strong current regions, with the zonal direction of the mean flow being prescribed. The major difference between the two methods resides in the form of the velocity profile, which is not imposed in our Method but is determined by the data themselves. Moreover, our Method is flexible enough to include information on any well-established countercurrents or flows having different zonal directions within a given current system. By tuning $\alpha_{\max }$, the Method also yields a velocity field that approaches observations quite closely.

[36] Finally, it is worth noting that we have used a single parameter $\alpha_{\max }$ that is common to a whole study area. In order to further increase the overall performance of the Method, it would be possible to divide the study area into several subareas and then find the best-fitting $\alpha_{\max }$ relevant to each. Such a refinement may be particularly useful for relatively well-exploited regions such as the Gulf Stream area. For many other parts of the world's oceans, however, this approach would appear to be premature because longterm current measurements are still lacking. The mean velocity statistics in those subareas are not always accurate or complete, independent of the fact that altimeter data are not free from errors either. The more measurements there are, the better will be the performance of the Method.

[37] Acknowledgments. Constructive comments from A. Colin de Verdière, R. T. Pollard, and two anonymous reviewers are greatly appreciated. A. C. Coward generously provided us with the OCCAM output data. Many thanks go also to T. M. Thèveny, who prepared the altimeter data, and to I. Durand, who improved the graphical presentation of the results. This work is a contribution (Y.-H. P. as a Principal Investigator) to the National Aeronautics and Space Administration/Centre National d'Etudes Spatiales (NASA/CNES) Joint Research Project for the TOPEX/Poseidon and JASON altimeter missions and has been partially supported by the Programme National d'Etudes de la Dynamique du Climat (PNEDC) and the CNES.

\section{References}

Chelton, D. B., M. G. Schlax, D. L. Witter, and J. G. Richman (1990), Geosat altimeter observations of the surface circulation of the Southern Ocean, J. Geophys. Res., 95, 17,877-17,903.

Chelton, D. B., J. C. Ries, B. J. Haines, L.-L. Fu, and P. S. Callahan (2001), Satellite altimetry, in Satellite Altimetry and Earth Sciences, edited by L.-L. Fu and A. Cazenave, pp. 1-131, Academic, San Diego, Calif.

Cheney, R. E., L. Miller, R. Agreen, N. Doyle, and J. Lillibridge (1994), TOPEX/Poseidon: The 2-cm solution, J. Geophys. Res., 99, 24,55524,563.

Ducet, N., P.-Y. Le Traon, and G. Reverdin (2000), Global high-resolution mapping of ocean circulation from TOPEX/Poseidon and ERS-1 and -2, J. Geophys. Res., 105, 19,477-19,498.

Feron, R. C. V., W. P. M. De Ruijter, and P. J. van Leeuwen (1998), A new method to determine the mean sea surface dynamic topography from satellite altimeter observations, J. Geophys. Res., 103, 1343-1362.

Fratantoni, D. M. (2001), North Atlantic surface circulation during the 1990 s observed with satellite-tracked drifters, J. Geophys. Res., 106, 22,067-22,093.

Fu, L.-L., and A. Cazenave (Ed.) (2001), Satellite Altimetry and Earth Sciences, 463 pp., Academic, San Diego, Calif.

Fukumori, I., R. Raghunath, and L.-L. Fu (1998), Nature of global largescale sea level variability in relation to atmospheric forcing: A modelling study, J. Geophys. Res., 103, 5493-5512.

Gill, A. E. (1982), Atmosphere-Ocean Dynamics, 666 pp., Academic, San Diego, Calif.

Gille, S. T. (1994), Mean surface height of the Antarctic Circumpolar Current from Geosat data: Method and application, J. Geophys. Res., 99, 18,255-18,273.

Gilson, J., D. Roemmich, B. Cornuelle, and L.-L. Fu (1998), Relationship of TOPEX/Poseidon altimetric height to steric height and circulation in the North Pacific, J. Geophys. Res., 103, 27,947-27,965.

Kelly, K. A., and S. T. Gille (1990), Gulf Stream surface transport and statistics at $69^{\circ} \mathrm{W}$ from the Geosat altimeter, J. Geophys. Res., 95, 3149-3161.

Le Traon, P.-Y., and F. Ogor (1998), ERS-1/2 orbit improvement using TOPEX/Poseidon: The 2-cm challenge, J. Geophys. Res., 103, 80458057.

Levitus, S. and T. P. Boyer (1994), World Ocean Atlas 1994, vol. 4, Temperature, NOAA Atlas NESDIS 4, 129 pp., Natl. Oceanic and Atmos. Admin., Silver Spring, Md.

Levitus, S., R. Burgett, and T. P. Boyer (1994), World Ocean Atlas 1994, vol. 3, Salinity, NOAA Atlas NESDIS 3, 111 pp., Natl. Oceanic and Atmos. Admin., Silver Spring, Md.

Mitchum, G. T. (1994), Comparison of TOPEX sea surface heights and tide gauge sea levels, J. Geophys. Res., 99, 24,541-24,554.

Nerem, R. S., et al. (1994), Gravity model development for TOPEX/ Poseidon: Joint Gravity Models 1 and 2, J. Geophys. Res., 99, $24,421-24,447$

Park, Y.-H. (2001), Interannual sea level variability in the Southern Ocean within the context of global climate change, AVISO Newsl., 8, 95-96.

Park, Y.-H., and L. Gambéroni (1995), Large-scale circulation and its variability in the south Indian Ocean from TOPEX/Poseidon altimetry, J. Geophys. Res., 100, 24,911-24,929. 
Park, Y.-H., and L. Gambéroni (1997), Cross-frontal exchange of Antarctic Intermediate Water and Antarctic Bottom Water in the Crozet Basin, Deep Sea Res., Part II, 44, 963-986.

Park, Y.-H. and B. Saint-Guily (1992), Sea level variability in the CrozetKerguelen-Amsterdam area from bottom pressure and Geosat altimetry, in Sea Level Changes: Determination and Effects, Geophys. Monogr. Ser., vol. 69, edited by P. L. Woodworth et al., pp. 117-131, Int. Union of Geodesy and Geophys., Toronto, Canada.

Park, Y.-H., L. Gambéroni, and E. Charriaud (1993), Frontal structure, water masses, and circulation in the Crozet Basin, J. Geophys. Res., $98,12,361-12,385$

Park, Y.-H., R. T. Pollard, J. F. Read, and V. Leboucher (2002), A quasisynoptic view of the frontal circulation in the Crozet Basin during the Antares-4 cruise, Deep Sea Res., Part II, 49, 1823-1842.

Qiu, B., K. A. Kelly, and T. M. Joyce (1991), Mean flow and variability in the Kuroshio Extension from Geosat altimeter data, J. Geophys. Res., 96 $18,491-18,507$
Schmitz, W. J., Jr. (1996), On the World Ocean Circulation, vol. I, Some Global Feature/North Atlantic Circulation, Tech. Rep. WHOI-96-03, 141 pp., Woods Hole Oceanogr. Inst., Woods Hole, Mass.

Stammer, D., C. Wunsch, and R. M. Ponte (2000), De-aliasing of global high-frequency barotropic motions in altimeter observations, Geophys. Res. Lett., 27, 1175-1178.

Tierney, C., J. Wahr, F. Bryan, and V. Zlotnicki (2000), Short-period oceanic circulation: Implications for satellite altimetry, Geophys. Res. Lett., 27, $1255-1258$

Verstraete, J. M., and Y.-H. Park (1995), Comparison of TOPEX/Poseidon altimetry and the in situ sea level data at Sao Tome Island, Gulf of Guinea, J. Geophys. Res., 100, 25,129-25,134.

Y.-H. Park, Département des Milieux et Peuplements Aquatiques, Muséum National d'Histoire Naturelle, 43 rue Cuvier, 75005 Paris, France. (yhpark@mnhn.fr) 